\title{
How precipitation and grazing influence the ecological functions of drought-prone grasslands on the northern slopes of the Tianshan Mountains, China?
}

\author{
HUANG Xiaotao ${ }^{1,2,3,4}$, LUO Geping ${ }^{3,4 *}$, CHEN Chunbo ${ }^{3,4}$, PENG Jian ${ }^{5 *}$, ZHANG Chujie ${ }^{5}$, \\ ZHOU Huakun $^{1,2,4}$, YAO Buqing ${ }^{1,2,4}$, MA Zhen ${ }^{1,2,4}$, XI Xiaoyan ${ }^{6}$ \\ ${ }^{1}$ Qinghai Provincial Key Laboratory of Restoration Ecology for Cold Regions, Northwest Institute of Plateau Biology, Chinese \\ Academy of Sciences, Xining 810008, China; \\ ${ }^{2}$ Key Laboratory of Adaptation and Evolution of Plateau Biota, Chinese Academy of Sciences, Xining 810008, China; \\ ${ }^{3}$ State Key Laboratory of Desert and Oasis Ecology, Xinjiang Institute of Ecology and Geography, Chinese Academy of \\ Sciences, Urumqi 830011, China; \\ ${ }^{4}$ University of Chinese Academy of Sciences, Beijing 100049, China; \\ ${ }^{5}$ Xinjiang Grassland Technical Popularization Station, Urumqi 830049, China; \\ ${ }^{6}$ Qinghai Environmental Sciences Research and Design Institute Co. Ltd., Xining 810007, China
}

\begin{abstract}
Drought-prone grasslands provide a critical resource for the millions of people who are dependent on livestock for food security. However, this ecosystem is potentially vulnerable to climate change (e.g., precipitation) and human activity (e.g., grazing). Despite this, the influences of precipitation and grazing on ecological functions of drought-prone grasslands in the Tianshan Mountains remain relatively unexplored. Therefore, we conducted a systematic field investigation and a clipping experiment (simulating different intensities of grazing) in a drought-prone grassland on the northern slopes of the Tianshan Mountains in China to examine the influences of precipitation and grazing on aboveground biomass (AGB), soil volumetric water content (SVWC), and precipitation use efficiency (PUE) during the period of 2014-2017. We obtained the meteorological and SVWC data using an HL20 Bowen ratio system and a PR2 soil profile hydrometer, respectively. We found that AGB was clearly affected by both the amount and seasonal pattern of precipitation, and that PUE may be relatively low in years with either low or excessive precipitation. The PUE values were generally higher in the rapid growing season (April-July) than in the entire growing season (April-October). Overall, moderate grazing can promote plant growth under water stress conditions. The SVWC value was higher in the clipped plots than in the unclipped plots in the rapid growing season (April-July), but it was lower in the clipped plots than in the unclipped plots in the slow growing season (August-October). Our findings can enhance the understanding of the ecological effects of precipitation and grazing in drought-prone grasslands and provide data that will support the effective local grassland management.
\end{abstract}

Keywords: climate change; human activity; aboveground biomass; precipitation use efficiency; soil volumetric water content; water stress

Citation: HUANG Xiaotao, LUO Geping, CHEN Chunbo, PENG Jian, ZHANG Chujie, ZHOU Huakun, YAO Buqing, MA Zhen, XI Xiaoyan. 2021. How precipitation and grazing influence the ecological functions of drought-prone grasslands on the northern slopes of the Tianshan Mountains, China? Journal of Arid Land, 13(1): 88-97. https://doi.org/10.1007/s40333-020-0078-6

*Corresponding author: LUO Geping (E-mail: luogp@ms.xjb.ac.cn); PENG Jian (E-mail: pengjian1213@163.com)

Received 2019-04-29; revised 2020-03-31; accepted 2020-05-28

(C) Xinjiang Institute of Ecology and Geography, Chinese Academy of Sciences, Science Press and Springer-Verlag GmbH Germany, part of Springer Nature 2021 


\section{Introduction}

Grassland ecosystems are widely distributed on the global land surface and are important in terms of both their economic and ecological value (Leroy et al., 2018; Yang et al., 2019). However, overexploitation of grasslands has led to their degradation becoming increasingly widespread in recent decades (Zhang et al., 2018; Yang et al., 2019). Grazing is one of the most common uses of grasslands and interacts with changing climate conditions to drive changes in plant growth (Bai et al., 2012; Guo et al., 2018). Significant differences in the natural environment, types, and grazing management of grasslands, and in the research methods applied to their study, have resulted in broad controversies concerning whether or not grazing improves grassland productivity (Xu et al., 2013; Huang et al., 2018; Zhang et al., 2018). In addition, the natural environmental conditions and grazing management techniques with potential to improve grassland production are poorly understood, which is not conducive to grassland management. Studying the ecological effects of precipitation and grazing in drought-prone grasslands is, therefore, increasingly important and of practical relevance. Such research will contribute to improvements in forecasting the responses of terrestrial vegetation to climate change and human activity, and in adopting effective adaptive strategies.

Research into the primary productivity of grassland ecosystems is generally based on aboveground biomass (AGB), which is defined as the yield of aboveground fresh grass or hay harvested at a certain time (Ren et al., 2018). It is an important indicator in evaluating ecosystem structure and function, and the most important parameter used in determining the sensitivity of grasslands to climate change and human activity (Zhang et al., 2018). Soil volumetric water content (SVWC) is the most important factor restricting plant growth in arid regions. The dynamic of SVWC is influenced by various factors, such as precipitation, evapotranspiration, and human activity (Zhang et al., 2016; Huang et al., 2018). Precipitation use efficiency (PUE) allows the coupling between precipitation and terrestrial ecosystem carbon cycles to be understood. It also indicates the efficiency with which plants use precipitation to produce biomass; a high PUE value indicates that vegetation can produce sufficient photosynthates despite limited water resources (Moreno-de las Heras et al., 2018; Ojeda et al., 2018). These three parameters, namely, AGB, SVWC, and PUE, are therefore the subject of substantial attention among scientists and grassland managers.

In this context, the dynamics of AGB, SVWC, and PUE are important for determining the most efficient use of grassland resources; additionally, an understanding of their dynamics would assist in achieving sustainable utilization of grassland resources, particularly in drought-prone regions. Grasslands are fragile under drought conditions due to the shortage of water resources and become highly sensitive in response to climate change and human activity (Ren et al., 2018; Zhou et al., 2018). Under drought conditions, precipitation is considered a limiting factor significantly affecting SVWC and plant growth (Luo et al., 2012; Stuart-Haëntjens et al., 2018). Some studies have shown that the high precipitation corresponds to a high SVWC, which in turn corresponds to a high AGB in drought-prone grasslands (Heisler-White et al., 2008; Mueller et al., 2016). Gherardi and Sala (2019), however, reached a different conclusion, finding that precipitation variability has a negative effect on aboveground net primary production (ANPP). Some studies have shown that ecosystem PUE increases with increasing precipitation (Jiang et al., 2017; Sun et al., 2017), however, some revealed that ecosystem PUE decreases with increasing precipitation (Xu et al., 2013). Therefore, it is still uncertain how precipitation influences plant growth.

The Tianshan Mountains are located in the hinterland of Eurasia; arid grasslands are widely distributed in this region (Luo et al., 2012; Huang et al., 2017a; Zhang et al., 2018) and are an important base for animal husbandry production (Liu et al., 2016). They also provide a natural laboratory for studying how precipitation influences the ecological functioning of drought-prone grasslands (Luo et al., 2012). Identifying the impacts of precipitation and grazing on the dynamics of AGB, SVWC, and PUE would be conducive to both quantifying plant growth and providing a scientific foundation for planning appropriate scales of livestock farming in the region. However, studies on this topic remain limited. Luo et al. (2012) used model simulations to show that 
moderate grazing can increase the ANPP of grasslands under water stress conditions, but their results have not been verified by experimental data. There has been no systematic and explicit investigation into how precipitation and grazing influence AGB, SVWC, and PUE in the Tianshan Mountains, although it is known that precipitation is the most significant factor limiting plant growth in the region (Huang et al., 2017a; Gherardi and Sala, 2019). Moreover, the relatively large interannual variation in precipitation observed in the Tianshan Mountains (Xu et al., 2018) may result in interannual differences in plant growth. The increase in grazing intensity has led to serious degradation of grasslands in this region (Huang et al., 2017a, 2018). Thus, there is an urgent need to understand how both precipitation and grazing affect interannual plant growth in drought-prone grasslands of the Tianshan Mountains.

Technological advances have led to major improvements in the availability and precision of experimental instruments. Field observations are more accurate than remote sensing and modelling (Huang et al., 2017b; Martínez-García et al., 2017; Marshall et al., 2018). Therefore, we used field observations of AGB, SVWC, and precipitation data during the period of 2014-2017 to identify how precipitation and grazing influence the ecological functions of a drought-prone grassland on the northern slopes of the Tianshan Mountains. Our study objectives are to examine the influences of precipitation and grazing on AGB and SVWC, and the influence of precipitation on PUE, in this drought-prone grassland.

\section{Materials and methods}

\subsection{Study site}

The experimental site $\left(43^{\circ} 33^{\prime} \mathrm{N}, 87^{\circ} 12^{\prime} \mathrm{E} ; 1648 \mathrm{~m}\right.$ a.s.l. $)$ is located in a typical drought-prone grassland on the northern slopes of the Tianshan Mountains in Xinjiang Uygur Autonomous Region (with the capital city of Urumqi), China. The terrain of the selected area is relatively flat and the vegetation, mostly composed of Gramineae, grows uniformly (Fig. 1). Typical chestnut soil occurs with silt as the main component of soil particles; grass roots are mainly distributed at soil depths of $0-40 \mathrm{~cm}$, particularly $0-15 \mathrm{~cm}$. The growing season extends from the beginning of April to the beginning of October. The average wind speed is approximately $2 \mathrm{~m} / \mathrm{s}$. The annual average air temperature is approximately $8^{\circ} \mathrm{C}$ (Huang et al., 2018). The average air temperature in

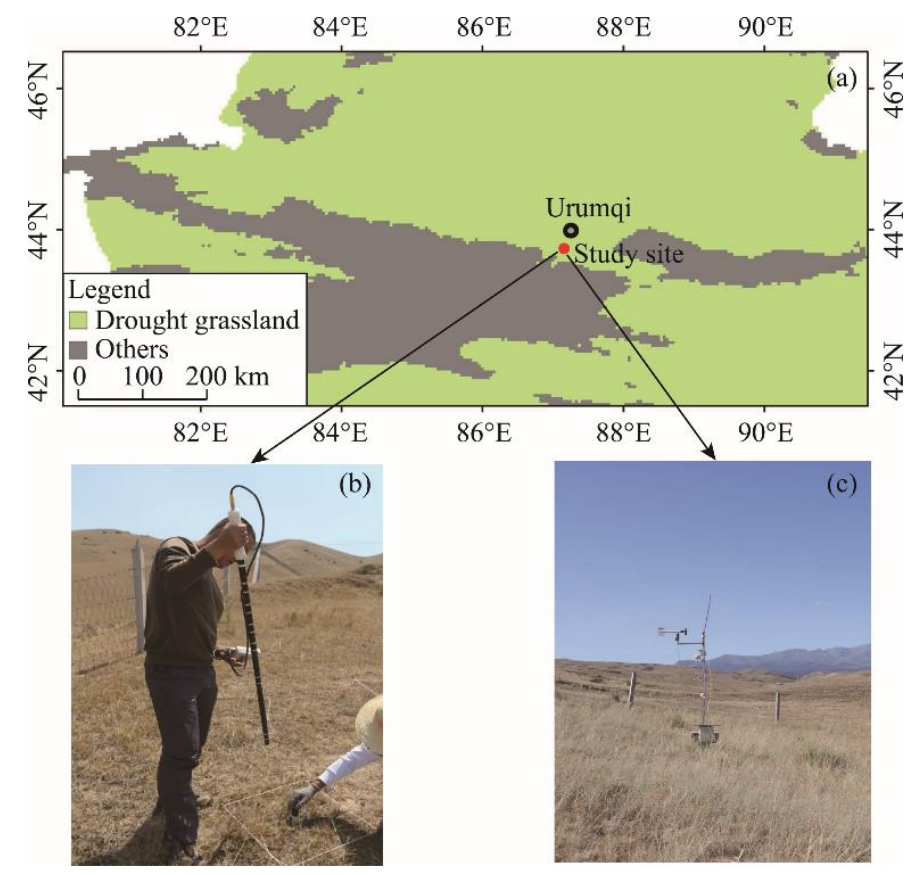

Fig. 1 Location of the study site (a) and demostration of the field experiments (b and c) 
summer is about $18^{\circ} \mathrm{C}$, and it rises rapidly in spring and decreases rapidly in autumn (Liu et al., 2016; Huang et al., 2017b). The land surface is covered by snow throughout winter; in spring, snowmelt has a positive role in promoting plant growth. Precipitation is relatively low and concentrated in spring and summer (Huang et al., 2017b). This arid climate causes water stress, and plants at this location enter dormancy in summer (primarily in August) (Huang et al., 2017b). Precipitation is considered the only source of water available for grass growth in this region, exerting significant influence on plant growth. The grassland provides important pasture, but it has become increasingly degraded due to overgrazing (Luo et al., 2012; Huang et al., 2017a, b).

\subsection{Experimental design}

In 2012, a $100 \mathrm{~m} \times 100 \mathrm{~m}$ fenced enclosure was set up at the experimental site. An HL20 Bowen ratio system (Jauntering International Corporation, Taiwan of China) was installed inside the enclosure to obtain daily meteorological data. Bowen ratio measurements are widely used because of their high accuracy and relatively low cost. We established eight groups (each comprised six $0.5 \mathrm{~m} \times 0.5 \mathrm{~m}$ plots (plot \#1 to plot \#6)) within the $100 \mathrm{~m} \times 100 \mathrm{~m}$ fenced enclosure to record AGB under different treatments during the period of 2014-2017. The distance between groups was over $3 \mathrm{~m}$, and the distance between plots within each group was $1 \mathrm{~m}$. Plant growth was uniform in the plots. Different intensities of clipping were conducted in plots \#1 to \#5 within each group, to simulate different intensities of grazing, and AGB was recorded for each plot. In each year, clipping experiments were conducted on 15 May, 6 June, 10 July, 10 August, and 3 October. The SVWC data from plots \#1 and \#5 were measured at 0-10, 10-20, and 20-30 cm depth using a PR2 soil profile hydrometer (DELTA-T, Cambridge, UK) (Fig. 2). SVWC at these depths might clearly be influenced by precipitation and human activity. During the growing season, when clipping was conducted, plants in plot \#1 were cut to ground level, and plants in plots \#2, \#3, and \#4 were cut to a stubble height of 3,5, and $8 \mathrm{~cm}$, respectively. Plot \#5 was unclipped and used as the control. To obtain AGB during the rapid growing season (April-July) of each year, we conducted clipping experiments in plot \#6 on 31 July. Plants in all plots were cut to ground level at the end of the growing season (October), and the plant material was transferred to the laboratory. The plant material was oven-dried at $65^{\circ} \mathrm{C}$ for $24 \mathrm{~h}$ in preparation for determining AGB values. We performed identical treatments in the same plots during the period of 2014-2017.

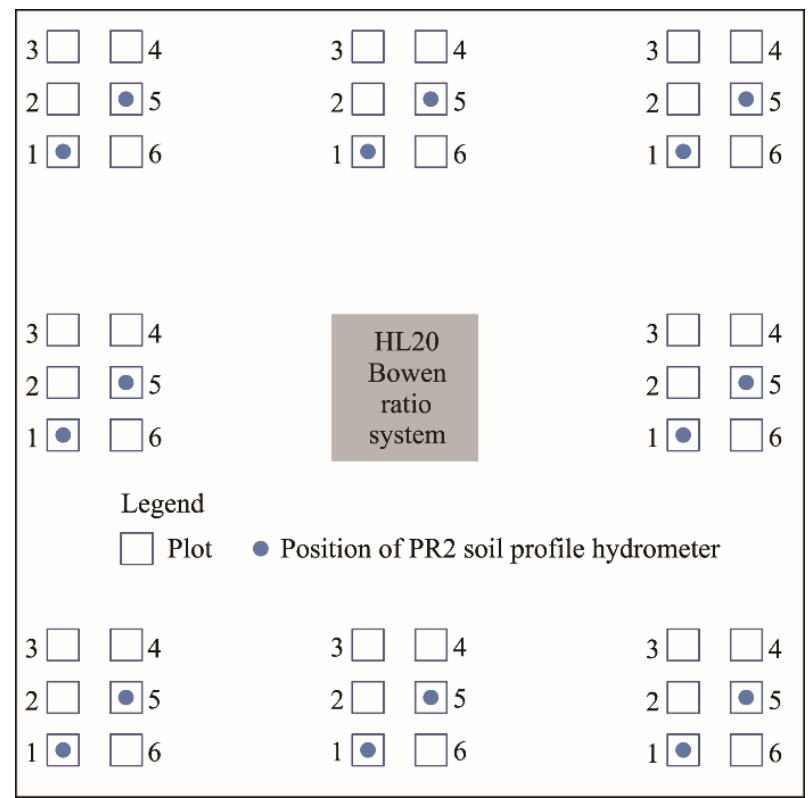

Fig. 2 Experimental layout 


\subsection{Statistical analysis}

We calculated the arithmetic means acquired from the plots subject to the same treatment conditions to determine the AGB and SVWC values for each treatment. PUE value was calculated as the ratio of ANPP value to precipitation; ANPP value was calculated as: $A N P P=A G B \times 0.45$ (Luo et al., 2012). All data were calculated and analyzed in Microsoft Excel 2010 (Microsoft Corporation, USA).

\section{Results}

\subsection{Precipitation, AGB, and PUE in the rapid and entire growing seasons}

According to the data collected in the rapid (April to July) and entire (April to October) growing seasons during the period of 2014-2017, precipitation was the highest in 2015 compared with the other years; however, the AGB was not the highest in 2015 (Table 1). In this year (2015), precipitation was concentrated in August, when vegetation had entered its aestivation period; abundant and high-intensity precipitation caused an increase in runoff. The intense precipitation in August would therefore not have had a significant impact on the AGB values in the rapid and entire growing seasons, as it was not available during the active growing period. In contrast, the AGB values were high in 2016, which was due to the high available precipitation in this year (Table 1).

Table 1 Precipitation (P), aboveground biomass (AGB), and precipitation use efficiency (PUE) in the rapid (April to July) and entire (April to October) growing seasons during the period of 2014-2017

\begin{tabular}{|c|c|c|c|c|c|c|c|c|}
\hline & \multicolumn{2}{|c|}{2014} & \multicolumn{2}{|c|}{2015} & \multicolumn{2}{|c|}{2016} & \multicolumn{2}{|c|}{2017} \\
\hline & Apr-Jul & Apr-Oct & Apr-Jul & Apr-Oct & Apr-Jul & Apr-Oct & Apr-Jul & Apr-Oct \\
\hline $\mathrm{P}(\mathrm{mm})$ & 162.0 & 212.8 & 221.8 & 402.8 & 195.8 & 206.0 & 160.0 & 206.0 \\
\hline $\operatorname{AGB}\left(\mathrm{g} \mathrm{C} \mathrm{m}^{2}\right)$ & 114.1 & 132.1 & 118.4 & 151.2 & 216.7 & 241.0 & 118.9 & 119.1 \\
\hline PUE $\left(\mathrm{g} \mathrm{C} /\left(\mathrm{m}^{2} \cdot \mathrm{mm}\right)\right)$ & 0.32 & 0.28 & 0.24 & 0.17 & 0.50 & 0.53 & 0.33 & 0.26 \\
\hline
\end{tabular}

Values of AGB and PUE fluctuated widely in the study site during the period of 2014-2017 (Table 1). The highest AGB value in the entire growing season occurred in 2016 (49.83\% higher than the average AGB value of 2014-2017), followed by the AGB value in 2015 (6.00\% lower than the average AGB value of 2014-2017). The lowest AGB value in the entire growing season occurred in 2017, when there was low precipitation, severe drought, and poor vegetation growth. The values of AGB in the rapid growing season (April-July) accounted for the majority of the AGB values in the entire growing season during the period of 2014-2017. The field survey indicated that vegetation grew most rapidly in April-July, and most plants began to wilt or entered aestivation in August. Some plants ended aestivation in autumn and continued to grow slowly. In the rapid growing season, the AGB value was higher in 2017 than in 2014. However, in the entire growing season, the AGB value was lower in 2017 than in 2014. The PUE values were generally higher in the rapid growing season (April-July) than in the entire growing season (April-October). In 2016, the PUE values were markedly higher than those in 2014, 2015, and 2017. In particular, in the entire growing season, the PUE value in 2016 was $70.97 \%$ higher than the average value of 2014-2017, and in the rapid growing season, the PUE value in 2016 was $43.88 \%$ higher than the average value of 2014-2017. In 2015, the PUE values were markedly lower than those in 2014, 2016, and 2017. In the entire growing season, the PUE value in 2015 was $45.16 \%$ lower than the average value of 2014-2017, and in the rapid growing season, the PUE value in 2015 was $30.94 \%$ lower than the average value of 2014-2017 (Table 1).

\subsection{AGB values in plots with different stubble heights}

In 2014, plots with plants clipped to ground level showed an ultra-compensatory growth, while plots with a remaining stubble height of 3,5 , and $8 \mathrm{~cm}$ showed a less compensatory growth (Fig. 3). This seemed to indicate that heavy grazing promotes plant growth. However, heavy clipping in 
2014 resulted in the degradation of grassland, and plots with plants clipped to ground level during the period of 2015-2017 showed a reduced compensatory growth. In contrast, ultra-compensatory growth was observed during the period of 2015-2017 in plots with a stubble height of $8 \mathrm{~cm}$. This indicated that moderate grazing can promote plant growth in the longer term.

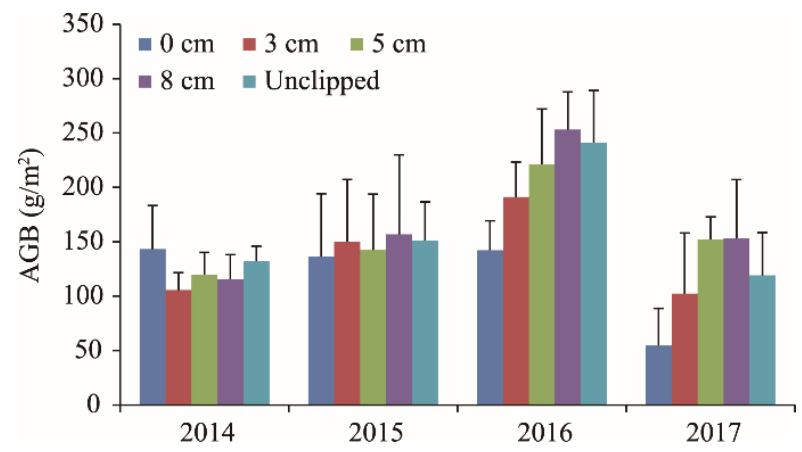

Fig. 3 Aboveground biomass (AGB) values in plots with different stubble heights $(0,3,5$, and $8 \mathrm{~cm}$, and unclipped) in the study site during the period of 2014-2017. The error bar represents the fluctuation range of the observed value.

\subsection{SVWC values in the entire growing season}

In the rapid growing season (April-July) of vegetation, the SVWC values decreased more rapidly in the unclipped plots than in the clipped plots (Fig. 4), indicating that the SVWC values were higher in the clipped plots than in the unclipped plots for a certain period. In the slow growing
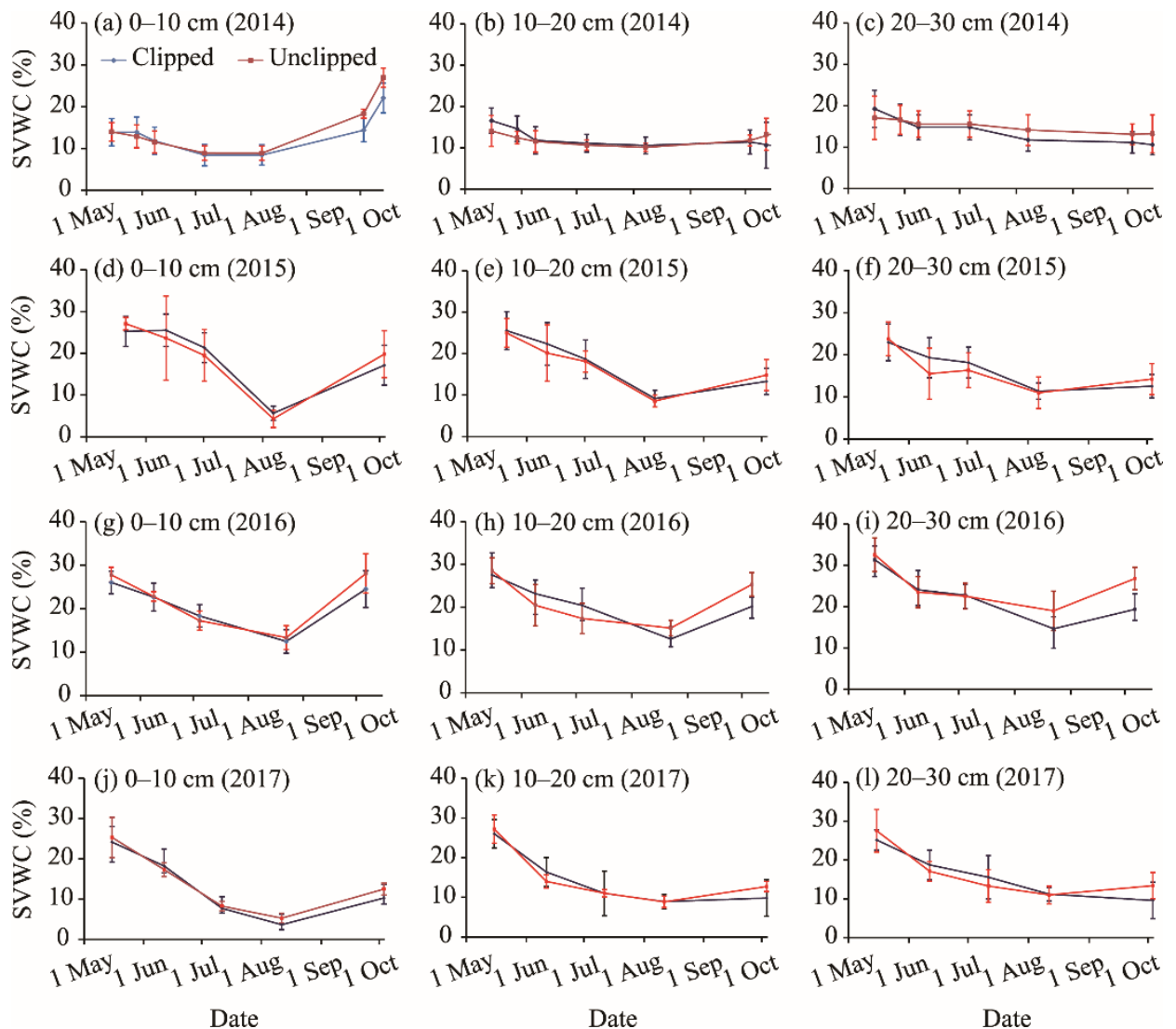

Fig. 4 Soil volumetric water content (SVWC) values in the clipped and unclipped plots at different soil depths $(0-10,10-20$, and $20-30 \mathrm{~cm})$ in the study site in the entire growing season during the period of 2014-2017. The error bar represents the fluctuation range of the observed value. 
season (August-October), clipping led to a lower SVWC value in the clipped plots than in the unclipped plots. Overall, the SVWC value was highest in spring in the entire growing season; it fluctuated more widely in the upper soil than in the underlying soil (Fig. 4).

\section{Discussion}

\subsection{Influences of precipitation on AGB, SVWC, and PUE}

Precipitation is a critical determinant of AGB in drought-prone grasslands (Huang et al., 2017a; Ming et al., 2018). Our results showed that the AGB is affected not only by the amount of precipitation but also by the seasonal pattern of precipitation, which is consistent with the findings of Peng et al. (2013). This hinders the ability to determine the contribution of precipitation to AGB in drought-prone grasslands on the northern slopes of the Tianshan Mountains; although precipitation is the dominant factor determining variation of AGB values in the region, precipitation itself varies considerably (Table 1; Fig. 3). Thus, there is substantial uncertainty regarding forage availability for livestock in the region.

The highest SVWC value observed in spring was due to the appearance of snowmelt, but the value decreased rapidly in summer because of the high evapotranspiration levels. In fact, due to the lack of water, plants entered aestivation and stopped growing in August 2015 even when there was a high summer precipitation. However, some of the vegetation continued to grow slowly in autumn, except when precipitation was low. These features reveal the specific physiological and ecological processes that have evolved as long-term adaptations to the arid environment. However, such adaptations have been poorly reported.

Our study shows that the PUE is not correlated with precipitation (Table 1). The PUE values may be low in years with either low or excessive precipitation; in the latter case, the increased precipitation may be unavailable to plants. Our results are similar to the findings of Paruelo et al. (1999), who found that the PUE value of grasslands is high under moderate water stress but low under both severe water stress and wet conditions. In this study, the PUE values were generally higher in the rapid growing season (April-July) than in the entire growing season; this could be a result of optimal hydrothermal conditions occurring during this period (Huang et al., 2017a, b).

\subsection{Influences of grazing on AGB and SVWC}

Substantial differences in the natural environment, grassland types, and research methods used in previous studies have led to broad controversies on whether grazing improves grassland productivity. Derner et al. (2006) suggested that grazing reduces grassland net primary productivity (NPP) in the Great Plains of North America, in contrast to observations made in some European grasslands (Milchunas and Lauenroth, 1993), where NPP increases under grazing. Luo et al. (2012) used model simulation and found that moderate grazing could promote ANPP under water stress, but their results have not been verified by field observation. Our study was based on experimental data provided by simulating grazing through clipping, and the results supported the hypothesis that moderate grazing can stimulate plant growth in drought-prone grasslands (Shi et al., 2017). Heavy clipping does not contribute to the conservation of SVWC in dry grasslands, and it can reduce the photosynthetic area of plants; these effects are not conducive to plant growth (Huang et al., 2017b; Ren et al., 2017). In contrast, tiller growth is promoted by moderate clipping, thus increasing the AGB (White et al., 2014). Grazing affects NPP by removing and trampling vegetation, and adding comprehensive nutrients to the soil in the form of faeces (Luo et al., 2012; Huang et al., 2018). Our clipping method simulated the removal of vegetation by livestock feeding, but did not simulate the influences of faeces and trampling on vegetation, which could not reasonably be controlled in the experiment. Nonetheless, our experimental data supported the hypothesis that moderate grazing can promote grassland productivity under water stress. In an actual grazing scenario, faeces can change soil properties, in particular water retention capacity, and could act as a fertiliser by promoting growth; additionally, moderate trampling can loosen the soil, exerting further positive effects on plant growth (Wittmer et al., 2010; Luo et al., 2012). However, heavy trampling has a negative effect 
on plant growth by increasing soil compaction (Pickering and Growcock, 2009; Striker et al., 2011). Thus, if experimental observations account for the effects of faeces and trampling, super-compensatory growth will be more evident under a moderate grazing scenario. In our study site, the SVWC values in the clipped plots were higher than those in the unclipped plots in the rapid growing season (April-July) of vegetation, which was due to the higher transpiration in the unclipped plots (Hu et al., 2009; Huang et al., 2017b). Thus, SVWC might explain why moderate grazing can improve grassland productivity under water stress conditions.

\section{Conclusions}

We conducted a systematic investigation into the influences of precipitation and grazing on AGB, SVWC, and PUE, based on experimental data collected in a drought-prone grassland on the northern slopes of the Tianshan Mountains during the period of 2014-2017. As the AGB was influenced by both the amount and seasonal pattern of precipitation, it was difficult to clarify the contribution of precipitation to AGB. The PUE value may be low in years with low precipitation, but it may also be low in years with excessive precipitation because of the large amount of unavailable precipitation. The PUE value was generally higher in the rapid growing season (April-July) than in the entire growing season (April-October). Our study verified experimentally that moderate grazing can promote grassland productivity under water stress conditions. In the rapid growing season (April-July), the SVWC values were higher in the clipped plots than in the unclipped plots; however, in the slow growing season (August-October), the SVWC values were lower in the clipped plots than in the unclipped plots. In theory, this study enhances our knowledge of the ecological effects of precipitation and grazing in drought-prone grasslands. In particular, it deepens our understanding of whether grazing improves grassland productivity. In practice, our findings help in determining how to balance forage supply and livestock forage requirements in order to avoid the risks of over-exploitation, thereby promoting sustainable development of drought-prone grasslands.

\section{Acknowledgements}

This research was funded by the Chinese Academy of Science (CAS) "Light of West China" Program (2018; Title: "The effect of grazing on grassland productivity in the basin of Qinghai Lake"), the Key R\&D and Transformation Projects in Qinghai Province of China (2018-SF-146), the Province Natural Foundation of Qinghai (2017-S-1-04, 2020-ZJ-925), the Xinjiang Uygur Autonomous Region Grassland Ecological Restoration and Subsidy Monitoring Support Project (XJCYZZ202001), and the Second Tibetan Plateau Scientific Expedition and Research Program (2019QZKK0302).

\section{References}

Bai Y F, Wu J G, Clark C M, et al. 2012. Grazing alters ecosystem functioning and C:N:P stoichiometry of grasslands along a regional precipitation gradient. Journal of Applied Ecology, 49(6): 1204-1215.

Derner J D, Boutton T W, Briske D D. 2006. Grazing and ecosystem carbon storage in the North American Great Plains. Plant and Soil, 280: 77-90.

Gherardi L A, Sala O E. 2019. Effect of interannual precipitation variability on dryland productivity: A global synthesis. Global Change Biology, 25(1): 269-276.

Guo T, Weise H, Fiedler S, et al. 2018. The role of landscape heterogeneity in regulating plant functional diversity under different precipitation and grazing regimes in semi-arid savannas. Ecological Modelling, 379: 1-9.

Heisler-White J L, Knapp A K, Kelly E F. 2008. Increasing precipitation event size increases aboveground net primary productivity in a semi-arid grassland. Oecologia, 158(1): 129-140.

Hu Z M, Yu G R, Zhou Y L, et al. 2009. Partitioning of evapotranspiration and its controls in four grassland ecosystems: application of a two-source model. Agricultural and Forest Meteorology, 149(9): 1410-1420.

Huang X T, Luo G P, He H L, et al. 2017a. Ecological effects of grazing in the northern Tianshan Mountains. Water, 9(12): 932, doi: 10.3390/w9120932. 
Huang X T, Luo G P, Wang X X. 2017b. Land-atmosphere exchange of water and heat in the arid mountainous grasslands of Central Asia during the growing season. Water, 9(10): 727, doi: 10.3390/w9100727.

Huang X T, Luo G P, Han Q F. 2018. Temporospatial patterns of human appropriation of net primary production in Central Asia grasslands. Ecological Indicators, 91: 555-561.

Huang Z, Miao H T, Liu Y, et al. 2018. Soil water content and temporal stability in an arid area with natural and planted grasslands. Hydrological Processes, 32(25): 3784-3792.

Jiang Y B, Zhang Y J, Zhu J T, et al. 2017. Effects of community structure on precipitation-use efficiency of grasslands in northern Tibet. Journal of Vegetation Science, 28(2): 281-290.

Leroy G, Hoffmann I, From T, et al. 2018. Perception of livestock ecosystem services in grazing areas. Animal, 12(12): 26272638.

Liu H, Zang R, Chen H Y H. 2016. Effects of grazing on photosynthetic features and soil respiration of rangelands in the Tianshan Mountains of Northwest China. Scientific Reports, 6: 30087, doi: 10.1038/srep30087.

Luo G P, Han Q F, Zhou D C, et al. 2012. Moderate grazing can promote aboveground primary production of grassland under water stress. Ecological Complexity, 11: 126-136.

Marshall M, Tu K, Brown J. 2018. Optimizing a remote sensing production efficiency model for macro-scale GPP and yield estimation in agroecosystems. Remote Sensing of Environment, 217: 258-271.

Martínez-García E, Rubio E, García-Morote F A, et al. 2017. Net ecosystem production in a Spanish black pine forest after a low burn-severity fire: Significance of different modelling approaches for estimating gross primary production. Agricultural and Forest Meteorology, 246: 178-193.

Milchunas D G, Lauenroth W K. 1993. Quantitative effects of grazing on vegetation and soils over a global range of environments. Ecological Monographs, 63(4): 327-366.

Ming G H, Hu H C, Tian F Q, et al. 2018. Precipitation alters plastic film mulching impacts on soil respiration in an arid area of Northwest China. Hydrology and Earth System Sciences, 22(5): 3075-3086.

Moreno-de las Heras M, Bochet E, Monleón V, et al. 2018. Aridity induces nonlinear effects of human disturbance on precipitation-use efficiency of Iberian woodlands. Ecosystems, 21: 1295-1305.

Mueller K E, Blumenthal D M, Pendall E, et al. 2016. Impacts of warming and elevated $\mathrm{CO}_{2}$ on a semi-arid grassland are non-additive, shift with precipitation, and reverse over time. Ecology Letters, 19(8): 956-966.

Ojeda J J, Caviglia O P, Irisarri J G N, et al. 2018. Modelling inter-annual variation in dry matter yield and precipitation use efficiency of perennial pastures and annual forage crops sequences. Agricultural and Forest Meteorology, 259: 1-10.

Paruelo J M, Lauenroth W K, Burke I C, et al. 1999. Grassland precipitation-use efficiency varies across a resource gradient. Ecosystems, 2: 64-68.

Peng S S, Piao S L, Shen Z H, et al. 2013. Precipitation amount, seasonality and frequency regulate carbon cycling of a semi-arid grassland ecosystem in Inner Mongolia, China: A modeling analysis. Agricultural and Forest Meteorology, 178179: 46-55.

Pickering C M, Growcock A J. 2009. Impacts of experimental trampling on tall alpine herbfields and subalpine grasslands in the Australian Alps. Journal of Environmental Management, 91(2): 532-540.

Ren H R, Zhou G S, Zhang F. 2018. Using negative soil adjustment factor in soil-adjusted vegetation index (SAVI) for aboveground living biomass estimation in arid grasslands. Remote Sensing of Environment, 209: 439-445.

Ren H Y, Eviner V T, Gui W Y, et al. 2018. Livestock grazing regulates ecosystem multifunctionality in semi-arid grassland. Functional Ecology, 32(12): 2790-2800.

Ren W B, Hu N N, Hou X Y, et al. 2017. Long-term overgrazing-induced memory decreases photosynthesis of clonal offspring in a perennial grassland plant. Frontiers in Plant Science, 8: 419, doi: 10.3389/fpls.2017.00419.

Shi G X, Yao B Q, Liu Y J, et al. 2017. The phylogenetic structure of AMF communities shifts in response to gradient warming with and without winter grazing on the Qinghai-Tibet Plateau. Applied Soil Ecology, 121: 31-40.

Striker G G, Mollard F P O, Grimoldi A A, et al. 2011. Trampling enhances the dominance of graminoids over forbs in flooded grassland mesocosms. Applied Vegetation Science, 14(1): 95-106.

Stuart-Haëntjens E, de Boeck H J, Lemoine N P, et al. 2018. Mean annual precipitation predicts primary production resistance and resilience to extreme drought. Science of the Total Environment, 636: 360-366.

Sun J, Du W P. 2017. Effects of precipitation and temperature on net primary productivity and precipitation use efficiency 
across China's grasslands. GIScience \& Remote Sensing, 54(6): 881-897.

White S R, Bork E W, Cahill Jr. J F. 2014. Direct and indirect drivers of plant diversity responses to climate and clipping across northern temperate grassland. Ecology, 95(11): 3093-3103.

Wittmer M H O M, Auerswald K, Schönbach P, et al. 2010. Do grazer hair and faeces reflect the carbon isotope composition of semi-arid C3/C4 grassland? Basic and Applied Ecology, 11(1): 83-92.

Xu M, Wu H, Kang S C. 2018. Impacts of climate change on the discharge and glacier mass balance of the different glacierized watersheds in the Tianshan Mountains, Central Asia. Hydrological Processes, 32(1): 126-145.

Xu X, Sherry R A, Niu S L, et al. 2013. Net primary productivity and rain-use efficiency as affected by warming, altered precipitation, and clipping in a mixed-grass prairie. Global Change Biology, 19(9): 2753-2764.

Yang S L, Hao Q, Liu H Y, et al. 2019. Impact of grassland degradation on the distribution and bioavailability of soil silicon: Implications for the Si cycle in grasslands. Science of the Total Environment, 657: 811-818.

Zhang D B, Yao P W, Na Z, et al. 2016. Soil water balance and water use efficiency of dryland wheat in different precipitation years in response to green manure approach. Scientific Reports, 6: 26856, doi: 10.1038/srep26856.

Zhang G L, Biradar C M, Xiao X M, et al. 2018. Exacerbated grassland degradation and desertification in Central Asia during 2000-2014. Ecological Applications, 28(2): 442-456.

Zhang H F, Sun Y, Chang L, et al. 2018. Estimation of grassland canopy height and aboveground biomass at the quadrat scale using unmanned aerial vehicle. Remote Sensing, 10(6): 851, doi: 10.3390/rs10060851.

Zhang R P, Liang T G, Guo J, et al. 2018. Grassland dynamics in response to climate change and human activities in Xinjiang from 2000 to 2014. Scientific Reports, 8: 2888, doi: 10.1038/s41598-018-21089-3.

Zhou G Y, Luo Q, Chen Y J, et al. 2018. Effects of livestock grazing on grassland carbon storage and release override impacts associated with global climate change. Global Change Biology, 25(3): 1119-1132. 